\title{
Reflexões Críticas sobre as Estratégias Instrucionais Construtivistas na Educação Científica
}

\author{
Critical Reflections about Constructivist Instructional Strategies in Science Education \\ Carlos Eduardo Laburú* e Sérgio de Mello Arruda \\ Departamento. de Física, Universidade Estadual de Londrina, \\ Cx. P. 6001, CEP 86051-970, Londrina, PR \\ laburu@uel.brrenop@uel.br
}

Recebido em 8 de abril, 2002. Aceito em 26 de setembro, 2002.

\begin{abstract}
Este trabalho procura contribuir com as críticas que vêm sendo realizadas na educação científica que tomam por base orientações instrucionais fundamentadas em pressupostos pedagógicos construtivistas. Além de mostrar os argumentos atuais que se opõem a essas orientações e pressupostos, procuramos ampliá-los e apresentar novos.
\end{abstract}

This work tries to contribute with criticism that is being conducted in science education on the basis of on instructional orientations grounded on constructivist pedagogical presuppositions. Besides showing current arguments that oppose these orientations and presuppositions, we intend to extend them and present new ones.

\section{Introdução}

Em função da crescente pressão educacional contrária à ineficácia de um tipo de instrução mecânica, sustentada em rotinas, na memorização, na precariedade da aprendizagem de conteúdos, em detrimento de competências e habilidades intelectuais de maior ordem, a educação científica, há mais de duas décadas, é extensamente influenciada pela teoria construtivista. Com a pretensão de ser uma descrição da atividade humana de conhecer, essa teoria procura especificar ações do ofício de ensinar e de aprender. Desde então, o movimento construtivista vem sendo a base para eufóricas recomendações para a prática de sala de aula.

Para o caso específico do ensino de ciências, o discurso construtivista, ao defender determinadas concepções epistemológicas e ontológicas (Laburú \& Silva 2000), que estão longe do consenso entre os pesquisadores da comunidade de educação científica (ver por exemplo, Matthews 2000; Irzik 2000; Airasian \& Walsh 1997; Nola 1997; Philips 1997; Osborne 1996), tende a sustentar uma determinada diretriz pedagógica que, por sua vez, é responsável por nortear ações metodológicas para a sala de aula. Estas últimas, igualmente, são alvo de contestação dos mesmos pensadores da educação científica exemplificados.

Este trabalho pretende se concentrar no levantamento dessas críticas às orientações instrucionais cons-

\footnotetext{
*Com ajuda parcial da Fundação Araucária
}

trutivistas, procurando discuti-las, complementar algumas e adicionar outras.

A título de esclarecimento, é importante ressalvar que o exame que faremos às orientações instrucionais construtivistas não deve ser visto como uma oposição sistemática ao movimento construtivista, mas é uma tentativa de mostrar que uma outra leitura pode ser dada a essas orientações e, ainda assim, achar-se abrigado pelos cânones construtivistas no ensino de ciências.

Adiantamos, também, que certas reflexões realizadas em relação às estratégias construtivistas talvez necessite de uma melhor compreensão dos seus fundamentos epistemológicos e ontológicos. No entanto, não pretendemos aprofundar a discussão desses fundamentos neste trabalho e passaremos à margem dos mesmos quando isto trouxer uma melhor compreensão do nosso interesse principal. Um maior aprofundamento das questões epistemológicas e ontológicas, no entanto, pode vir a ser encontrado em outro trabalho de um de nós (Laburú et al. 2001).

Entendemos que a importância em situar aqui as críticas educacionais enquadra-se, fundamentalmente, na perspectiva de quão distante estão certas orientações construtivistas que argumentam a necessidade evidente de uma mudança pedagógica e a efetiva evidência que documenta a eficácia dessa mudança. 


\section{Premissas construtivistas e apontamentos pedagógicos}

De forma sintética, podemos dizer que a influência metodológica construtivista no ensino de ciências se dá, inicialmente, através do chamado construtivismo radical, de inspiração piagetiana, tendo em Glasersfeld (1989) um dos seus principais teóricos. Nos anos oitenta, este movimento se frutifica e gera o modelo pedagógico de mudança conceitual, que absorve, em termos teóricos, as pesquisas empíricas sobre as concepções espontâneas dos aprendizes. Após, aproximadamente, uma década de investigações nesse referencial teórico, desponta a dissidente vertente construtivista social (Scott et al. 1991), que apresenta uma natureza pedagógica distinta, mantendo, contudo, similares fundamentos epistemológicos e ontológicos.

Antes de adentrarmos no foco principal da nossa discussão, permitimo-nos indicar alguns principais fundamentos construtivistas que norteiam, e devem auxiliar a compreender melhor, a leitura didática que aqui estaremos sujeitando a exame.

Sem dúvida que um pressuposto fundamental, largamente disseminado pelo movimento construtivista da educação científica, é o baseado na idéia do "aprendiz construtor do seu próprio conhecimento" (Driver 1989), que vem para a sala de aula com esquemas de pensamento e crenças preexistentes. Lembremos que tal pressuposto toma, como suporte inspirativo epistemológico, o ideal pós-positivista de que "toda observação é realizada à luz de uma teoria" (Popper 1972: 61).

$\mathrm{O}$ aprendiz autoconstrutor subentende, na postura construtivista radical, a elaboração do conhecimento como um processo eminentemente individual, compreendido que todo conhecimento é uma tentativa pessoal e subjetiva. Essencialmente, este movimento construtivista assume que os estudantes elaboram conhecimentos e crenças a partir dos seus conhecimentos preexistentes, submetendo-os às novas idéias e situações que eles encontram.

Esta posição construtivista, tipificada por uma linha cognitiva individual, é temperada pela divergente linha cognitiva sociocultural, aqui designada de construtivismo social ou sócio-construtivismo. Neste último, o conhecimento é visto como construído por um sujeito (estudante) em interação com o seu meio social (escola e cultura extra-escolar). O ponto importante é que os construtivistas sociais acreditam que a construção do conhecimento tem uma componente social e não pode ser considerada gerada por um indivíduo, agindo independentemente do seu contexto social. Em razão dos indivíduos ou contextos socioculturais diferirem, uma parte desses construtivistas inferem, portanto, que os significados que as pessoas fazem são únicos a si próprias ou relativas às suas culturas (Airasian \& Walsh 1997). Isto resulta potencialmente em tantos significados quanto houver pessoas ou grupos culturais. Essencialmente, então, o conhecimento nunca pode ser justificado como absoluto, verdadeiro ou mais verdadeiro, de um lado (opus cit.), ou correto ou válido, de outro (Laburú \& Silva 2000), pois tende a ser o produto de uma infinidade de significados, eqüivalente ao número de culturas ou de fatores contextuais existentes (Airasian \& Walsh 1997). A possibilidade de um significado universal para o conteúdo científico, que não recorra a nenhuma espécie de fator extracientífico social ou político, que traspasse o indivíduo ou o seu ambiente social, não é enfatizado por esse referencial (Airasian \& Walsh 1997: 445c; Chalmers 1994: 107).

Uma leitura ontológica e epistemológica, nesse sentido, que passa por uma interpretação doutrinária idealista e relativista ${ }^{1}$, legitima e acomoda apontamentos instrucionais que podem ser encontrados em muitos escritos construtivistas e que resumimos, junto com Airasian \& Walsh (1997), nas seguintes sentenças:

Impõe-se muita responsabilidade ao estudante na construção de significados e nas interpretações pessoais (Airasian \& Walsh 1997: 446).

O ônus de criar e adquirir conhecimento é transferido do professor para o estudante, emancipando o primeiro, num certo sentido, da responsabilidade da aprendizagem. Este não é mais um provedor de informações, mas está muito mais envolvido com o processo de aprendizagem, coordenando e provocando a construção pessoal do estudante. Consequentemente, o professor tem que aprender a guiar e não a dizer ou corrigir os alunos (Airasian \& Walsh 1997: 446, 448b). As palavras de ordem são: negociação e mediação.

O ensino, por transmissão verbal, tem por trás uma concepção de aluno "tábula rasa" e de aluno passivo. Tal ensino é um processo ineficiente e secundário de construir conhecimento, portanto, inviável pedagogicamente. "O compromisso central da posição construtivista é de que o conhecimento não é transmitido diretamente de quem conhece (Knower) a outro ..." (Driver et al. 1994: 5a) ou "o ensino direto de conceitos é impossivel e infrutifero" (Vygotsky apud Rego 1994: 78).

Desde que o conhecimento consiste no que é construído pelo aprendiz e desde que alcançar a verdade absoluta é impossível, todo estudante pode aprender e, portanto, construirá o conhecimento (Airasian \& Walsh 1997: 446b).

O que o estudante constrói é bom ou válido (ibid.).

A quantidade de tempo gasto com a aprendizagem não é importante (ibid.), pois cada aluno tem o seu tempo.

\footnotetext{
${ }^{1}$ Neste ponto vai uma primeira observação. Dizer que o aprendiz constrói o seu conhecimento individualmente não elimina a hipótese da existência de um mundo real. Ou seja, um certo pressuposto epistemológico (construção do conhecimento) não implica necessariamente um pressuposto ontológico (a não existência de um mundo real, ou seja, uma agenda idealista). Maiores detalhes ver Laburú et al. (2001).
} 
A aprendizagem é significativa quando o aluno chega à resposta ou à idéia de maneira independente.

O conteúdo passa a ser secundário (ibid.).

A autonomia, a construção e o interesse pessoal são elementos desencadeadores da motivação, estando em oposição a eles a obediência, a instrução e o reforço externo, respectivamente. O professor é emancipado da difícil tarefa de motivar, desde que se entende que são próprios do estudante os caminhos da aprendizagem (ibid., p. 446).

Enfase nas discussões em grupo ou coletiva.

Um processo discursivo coletivo, supostamente conquistado na esfera intermental da sala de aula, é apreendido intramentalmente pelos alunos.

É sempre possível partir das idéias prévias dos alunos e confrontá-las com novas experiências e conhecimentos $^{2}$. Logo, é importante extrair as idéias prévias dos alunos.

\section{Crítica aos apontamentos construtivistas}

Tendo em conta o levantamento acima e os comentários que o precederam, podemos começar por objetar a proposição individualista, suportada pelo construtivismo radical, que imputa ao nível do privado, do subjetivo, a aquisição das asserções do conhecimento, no caso, curricular. Essa abordagem, ao considerar a construção do conhecimento como sendo um processo eminentemente individual entre o que o aprendiz já conhece e as novas experiências, mostrou-se insuficiente em dar conta da complexidade das relações envolvidas no processo de ensino-aprendizagem. Dentro dessa visão, o aprendiz é, num sentido cognitivo, um ser solitário (Howe 1996) e o professor é entendido, tão somente, como um provocador, quando não, praticamente, um mero provedor e um organizador dos meios necessários ao desenvolvimento do aprendiz.

A valorização inicial dessa proposição (Rowell 1983a; Nussbaum \& Novik 1982) leva ao surgimento de estratégias de ensino centradas no conflito cognitivo, em que as idéias prévias do aluno são expostas e, em seguida, postas em conflito cognitivo. Imagina-se que elas são superadas e substituídas, a partir daí, por conceitos científicos mais coerentes. Investigações realizadas mostram que o conflito cognitivo, na seqüência precedente, não apresenta bons resultados pedagógicos (Rowell 1983), pois os alunos se protegem de várias maneiras dos conflitos, (Laburú et al. 1998; Laburú 1996; Chinn \& Brewer 1993; Rowell 1989; Karmiloff-Smith 1974). Por detrás de tais atribuições instrucionais são identificadas posturas empiristas ${ }^{3}$ (Jenkins 2000: 604; Matthews 1992, 1994), pois a discrepância empírica não é condição suficiente para que ela assim seja observada como tal. Em termos gerais, a crítica feita resume-se no seguinte: didaticamente falando, nenhuma experiência ou observação individual pode, de todo, estabelecer ou orientar a construção de conceitos científicos, que são, em última instância, construções abstratas, idealizadas.

No entanto, diversos construtivistas radicais, incluindo-se aqui muito mais os sociais, reconhecem que há um mundo público, simbólico, criado pela ciência, em que as crianças têm que ser introduzidas, e que tal processo envolve a internalização dos conceitos (por exemplo, Howe 1996; Mortimer \& Machado 1996; Driver et al. 1994; Edwards \& Mercer 1987). Em particular, os construtivistas sociais, ao contrário dos individualistas radicais, estão conscientes de que esse mundo não pode ser descoberto pelas crianças solitariamente, através de um inquirir privado. Ao não negarem a componente social na aprendizagem, claramente identificam no social a parte indispensável para um projeto de aprendizagem (Hardy \& Taylor 1997: 140; Airasian \& Walsh 1997). Na procura por uma saída para enfrentar o construtivismo individual, reconhecem que o conhecimento é um processo coletivo de "enculturação" nas idéias e modelos da ciência convencional (Driver et al., 1994). Como conseqüência dessa postura, dão uma justificação mais sustentada para que se proliferem atividades de ensino baseadas na discussão em grupo e na colaboração social.

Todavia, é certo que a participação, um tanto constante, do estilo discussão em grupo ou de discussão em geral, parece se estender para além do círculo pedagógico construtivista individual, alcançando também a vertente social. Para estes últimos, talvez, isto se deva a uma leitura desvirtuada, ou, digamos melhor, exagerada do trabalho de Vygotsky. Quando este autor coloca que é no grupo cultural onde o indivíduo nasce e se desenvolve, que lhe são fornecidas as formas culturalmente determinadas de perceber e organizar o real, que os processos psicológicos do indivíduo são internalizados a partir dos processos interpsicológicos (Oliveira 1993: 37, 97), não devemos esquecer que também para ele é fundamental que a alteração de desempenho de uma pessoa se dê por meio da interferência de outra. Isto quer dizer que um indivíduo tem a capacidade de se desenvolver e de se beneficiar de uma colaboração de outro indivíduo (opus cit.: 59). Tal proposição pode vir a ser entendida sem a enfática implicação e determinação de que, em praticamente a todo momento, se deva recorrer às discussões em grupo ou coletivas e, por outro lado, não é contraditória com a influência direta da exposição oral convencional, logo, assistência explícita do professor.

Além disso, o modelo cognitivo de aprendizagem dos construtivistas sociais, ao procurar se contrapor

\footnotetext{
${ }^{2}$ O que gera técnicas de conflito cognitivo (Scott et al. 1991, Rowell 1989, Nussbaum \& Novick 1982) ou por analogias e metáforas (Clement et al. 1987; Stavy 1991).

${ }^{3}$ Às quais o ideal construtivista procura se opor.
} 
ao construtivismo individual, não se liberta, em geral, dos problemas pedagógicos deste último e, ao mesmo tempo, chega a enfrentar alguns novos. Um deles é não proferir uma adequada explicação da forma como as componentes sociocultural e pessoal da aprendizagem interagem. Mais especificamente, fica a questão: o que se compreende, explicitamente, em termos didáticos, com a máxima "negociação" extensivamente empregada e que denota a idéia da interferência ou interação do "expert" (professor ou pares) com o noviço, por essa perspectiva construtivista? Por detrás dessa máxima parece haver o sentimento da existência de uma disfarçada proibição do "expert" (professor) poder dar direta e claramente a explicação ou dizer a resposta correta, ao novato. Os professores sob tal orientação ficam relutantes em fornecer a explicação correta para os seus alunos e parecem desconsiderar que cabe a eles corrigir (Jenkins 2000: 602) os entendimentos errados dos mesmos (Irzik 2000: 633, 634). Temos a oportunidade de constatar essa inabilidade pedagógica mais especificamente em Jenkins (2000), na medida em que se observa o caso de um professor primário que, preocupado com as pressões construtivistas, expressa a seguinte pergunta: (mas) "Quando eu devo dizer a resposta correta (aos meus alunos)?" (p. 605). Esse mesmo autor comenta que ao procurarmos no construtivismo a melhor condução para essa questão, notamos que ele é um guia que oferece pouco neste sentido (ibid.: 602).

Negociar, portanto, subentende uma imposição pedagógica de que o aprendiz deve alcançar o conhecimento de maneira independente, chegando à conclusão sempre e exclusivamente por si próprio. Ao "expert" (professor) caberia oferecer pistas, sugestões, caminhos e os meios, evitando dar a resposta direta (Hollon et al. 1991: 148), não lhe cabendo suprir informações (Airasian \& Walsh 1997: 446c). Isso é evidenciado quando se observa a descrição "ipsis verbis" de diálogo ocorrido entre alunos e professores, apresentados em certos escritos construtivistas. Como se pode ver dos mesmos, praticamente toda a fala discorrida pelo professor é baseada em questionamentos ou em reforço a alguma informação ou nova idéia válida do aluno, todavia pretendida pelo professor. Provavelmente, tal formato discursivo deve retratar com fidelidade, também, outra máxima construtivista muito difundida, simbolizada pela palavra chave "mediar", onde argumentos similares poder-lhe-iam ser aplicados.

Porém, como podemos lembrar, alguns desses encaminhamentos metodológicos construtivistas não são novos. O antigo modelo por descoberta já enfatizava que o professor não deveria dizer aos seus estudantes o princípio ou generalização ou regra que se esperasse que eles aprendessem (Bittinger: 1968). No fundo, o que gostaríamos de destacar é a crítica de Friedlander (1965) a esta orientação básica do modelo de descoberta, e que podemos estendê-la convenientemente às "semelhantes" pretensões construtivistas, na medida em que não há uma sólida evidência de que os "insights" que um estudante desenvolve por si mesmo são melhor lembrados que os "insights" aprendidos de outros.

Uma outra questão mais geral, apesar de ser de âmbito epistemológico, mas com imediatas implicações didáticas, refere-se ao subjetivismo inerente nas pretensões contrutivistas. Para o construtivismo radical, isso fica explicitado no individualismo, como dissemos. Contudo, tal postura é igualmente problemática para o construtivismo social. Só que, agora, a crítica básica é direcionada à defesa do subjetivismo coletivo ou endosso coletivo do conhecimento (Irzik 2000: 627) que, em termos instrucionais, é condutora da importância das discussões em grupo. Neste instante cabe, novamente, um questionamento pedagógico parecido àquele feito aos construtivistas individualistas: qual grupo de alunos ou num sentido mais geral, qual grupo social estará julgando correto o seu conhecimento (Matthews 1994: 161)? Ou, noutras palavras, partindo de tal ceticismo radical, como podemos estar certos de que grupos em sala de aula (ou num entendimento mais abrangente, na ciência), deixados independentes uns dos outros, formam um consenso entre si (Nola 1997: 74)? E, adicionalmente, como a negociação, de um lado, se traduz numa linguagem comum dentro do grupo e entre os $\operatorname{grupos}^{4}$ ou, por outro lado, a mediação, em relação à coletividade da sala de aula? Poderíamos dizer que, perigosamente, para certas leituras dos construtivistas sociais, presenciam-se noções de um discurso pedagógico que os aproxima da mesma problemática dos radicais privativos, pois, assim como estes, os primeiros, aparentemente, continuam sustentando que, apesar da interação social, é da eminente experiência individual que os aprendizes criam afirmações e significados próprios, quando da apropriação dos elementos sócioculturais. Assim, as palavras de ordem desses construtivistas como negociar, facilitar, conduzir, orientar, guiar, providenciar, mediar, entre outras, parecem denotar, semelhantemente a influência construtivista radical já mencionada, do sujeito autoconstrutor do seu conhecimento, apenas que, neste caso, o conhecimento é vivenciado a partir de uma evidência convencionada em comunidade.

A objeção à posição dos construtivistas sociais, que legitimamente se encaixam num entendimento deste tipo, portanto, é comparável à crítica subjetivistaindividualista feita aos construtivistas radicais, que se

\footnotetext{
${ }^{4}$ Uma outra linha de argumentação poderia vir a perguntar o seguinte. Será que o sujeito está sempre à mercê do capricho do grupo? A nossa resposta seria: nem sempre. No caso da sala de aula constata-se, quando se usa a técnica de estudo em grupo, que apesar de existirem alunos líderes em idéias dentro de certos grupos, ao mesmo tempo presenciam-se alunos que não aceitam a posição do líder e defendem idéias independentes (Laburú 1993: 87). Na ciência, muitas vezes, reconhecem-se grandes avanços quando indivíduos se atrevem a romper com conceitos admitidos pela coletividade científica.
} 
encontra difundida através da afirmação pedagógica de caráter geral, que aponta a necessidade de haver um mecanismo bem definido de ajuda ao indivíduo, afim de que ele possa, por si só, desenvolver e gerar novas idéias e conceitos para interpretar a experiência e transcender o pensamento de senso comum. Dada esta assertiva, poderíamos perguntar: que mecanismo, que tipo específico de intervenção ou de providências são essas, e de onde viriam as idéias para interpretar as percepções sensoriais e os novos conceitos? Para melhor esclarecer o que queremos dizer, suponhamos, no caso das percepções sensoriais, o exemplo de deixarmos um aprendiz, ou um grupo de aprendizes solidários, livremente a observar o movimento browniano de partículas de pólen com o auxílio de um microscópio. Nessa situação o aprendiz, ou aprendizes, neste caso, por intensa negociação consensual entre si, pode vir a inferir que o contexto no qual se dá o movimento dessas partículas é o biológico, em vez de localizá-lo no contexto físico, isto é, as partículas mover-se-iam, pois seriam pressupostas como corpúsculos vivos, logo, situa-as no contexto biológico e não no físico. Por outro lado, poderia voltar a sua atenção para o microscópio e não para o movimento em $\mathrm{si}^{5}$.

Como essa exemplificação nos pode fazer imaginar, uma observação solitária, ou solidária, pode encaminhar-se por vários caminhos e conduzir a diversas conclusões que, muitas vezes, são discrepantes daquelas objetivadas pelo instrutor. Neste sentido, Di Sessa (1982) e Irzik (2000: 634) apropriadamente nos lembram, respectivamente, que muito poucos estudantes, se é que existe algum, aprendem a física newtoniana, tratando com o mundo diário, e que é ingenuidade esperar que os estudantes descubram, por conta própria, as descobertas científicas. A respeito disso, Matthews (2000: 6) chama a atenção para a seguinte situação: por exemplo, quando empurramos um objeto e recebemos uma variedade de respostas sensoriais desta ação, isto não vai implicar que idéias de pressão, elasticidade, força, esforço e tensão sejam derivadas antes dessas palavras terem sido aprendidas e definidas. E acrescenta, "Definições (e significados) não são construídas (build up) pelo indivíduo, elas são 'aprendidas' pelo indivíduo" (opus cit.).

Deste modo, as palavras de ordem anteriores só seriam convincentes se a elas associássemos outras palavras de ordem basicamente centralizadas e dependentes das ações do professor, que poderiam ser, entre outras: conduzir, no sentido de estabelecer previamente o que vai ser estudado, dizendo o que é preciso ver; colocar, explicar e expor os novos conceitos, explicitando e organizando as novas informações de maneira clara; mostrar a (nova) forma de ver e o que precisa ser visto ou entendido; advertir e corrigir os entendimentos errados de cada aluno, sanando dificuldades; mostrar e comparar a estrutura conceitual oficial com a do aluno.
A complementar estas idéias, uma análise com maior destaque precisa ser feita em relação à linguagem, sem dúvida um instrumento pedagógico imprescindível por parte do professor. Para os construtivistas radicais, e como também se pode constatar explicitamente em representantes da linha social (ver, por exemplo, Driver et al., 1994: 5a; Vygotsky apud Rego 1994: 78), os elementos da linguagem, como as idéias, os conceitos e a palavra não podem ser transferidos de um usuário para outro. A linguagem, para eles, tem a sua principal apreciação alicerçada a partir do ponto de vista do subjetivo e não fora deste, ou seja, do agente transmissor. Porém, esta reação construtivista de que os elementos da linguagem não podem ser transferidos é óbvia, pois tais entidades são de natureza mental e não podem ser literalmente transferidas, como coloca Matthews (1994). Também, não se quer discutir aqui a inegável declaração de que elaborar uma linguagem requer do aprendiz atenção e atividade intelectual. Analogamente, é difícil polemizar que a referida atividade é um processo essencialmente autônomo, individual. Contudo, isso não implica que o indivíduo dê um significado exclusivamente subjetivo a uma estrutura conceitual, elaborando através da linguagem um discurso próprio. O que se constata de fato, pela própria possibilidade de comunicação inter-sujeitos, é que os significados individuais, através da instrução, vão ou deveriam ir se aproximando isomorficamente dos científicos (cf. também Mortimer \& Machado 2000). O exercício do processo educativo científico é o de aproximar melhor e o mais eficientemente possível, o discurso individual do coletivo oficial. Neste sentido, Matthews (1994: 156) chega a dizer que, na maior parte do tempo, o sujeito aprende e não constrói os significados e completa observando que, caso se dê ao sentido da palavra "transferir", acima, o de "poder ser ensinado", de "poder ser aprendido", ou mesmo de "poder ser assistido" o seu desenvolvimento, a asserção que afirma que o conhecimento não pode ser transferido ou transmitido vai de encontro ao bom senso; é incontestável que os pais instruem as crianças numa série enorme de assuntos e os professores em matérias complexas como matemática, ciências e história. Quem de nós não assistiu, em vídeo, uma palestra ou um debate, ou ainda, leu um bom livro e constatou que aprendeu muito com as idéias novas transmitidas pela linguagem escrita do autor ou, no primeiro caso, assistidas através do vídeo. Também é fácil verificar que quase a totalidade da comunicação e troca de informação inter-pessoal do dia a dia ou de um grupo de cientistas, produtores do conhecimento, dá-se via transmissão verbal direta, sem que exista nenhuma técnica construtivista especial por detrás. Além do mais, sabemos que a maior parte da tradição científica é passada de mão em mão e não reinventada por cada geração. Como poderia qualquer aprendiz reinventar

\footnotetext{
${ }^{5}$ Assim como o fizeram historicamente os cardeais críticos de Galileu, em relação à luneta astronômica (Feyerabend 1989).
} 
definições, conceitos e conhecimentos, se as melhores e as mais privilegiadas cabeças da história levaram anos ou séculos para elaborá-los? Ou, nas palavras de Jenkins (2000: 602), é ser otimista demais assumir que jovens estudantes possam construir explicações científicas que evoluíram tardiamente na história da humanidade, simplesmente observando fenômenos, gerando e testando hipóteses. O legado metodológico construtivista, indicando que a transferência de significado através da linguagem não implica que se possa aprender tudo o que é ensinado e de que há sempre uma incerteza nessa aprendizagem, é inegável. Como o é a noção de que deve existir uma atividade mental intensa para aprender um significado de um conceito. Mas, aí em dizer que significados não são passíveis de transferência, de que eu não posso fornecer às pessoas, numa audiência, qualquer novo conceito, mas apenas estimulá-los a combinar, de diferentes maneiras, os conceitos com as palavras que eu estou usando, é afrontar as evidências. Talvez, a falha para os que interpretam o construtivismo desta forma esteja em imaginar que em situações de verbalismos ou mesmo de atividades mecânicas não haja, muitas vezes, a ocorrência simultânea e o disparo de processos de internalização de novos significados, e que elas sejam sempre vazias ou estéreis, pedagogicamente falando. Assim, esta última posição, da superada tese ambientalista $^{6}$ (Rego 1994: 93), não pode obscurecer a legítima primeira posição, que, inclusive, é uma tese central sócio-interacionista construtivista, pois entende a interação do indivíduo com o seu meio cultural como definidora da constituição humana e, em particular, da aprendizagem (opus cit.).

Outra questão criticável, diz respeito à estratégia usada para ensinar e ao modo particularizado de aprender de cada um. Também, nesta situação, é difícil dar crédito à radical reação construtivista ao didatismo, quando valoriza em demasia a pedagogia do estilo discussão em grupo, estilo que é observado na medida em que há excessivo destaque das atividades desse tipo, fundamentadas na promulgada colaboração social para a produção do conhecimento. Como dissemos, "o falar", "o mostrar", típicas atividades expositivas, têm um papel ignorado nessa produção, ou é válida, ao que se presume, somente para e entre os pares - como nas discussões em grupo -, pelo menos, é a impressão que deixa a leitura de diversos trabalhos autodenominados construtivistas.

Detendo-nos um pouco mais na questão das discussões em grupo ou discussões coletivas, coloquemos duas reflexões. Antes, é preciso dizer que compreendemos que essas estratégias pedagógicas devam ter um importante papel socializador, como vimos alguém já destacar em outro lugar. Ambas também são responsáveis pelo fundamental papel de estímulo cognitivo dos aprendizes. Mas, e esse é o primeiro ponto de reflexão, ao observarmos trabalhos construtivistas onde são ilustradas interações dialógicas, pode-se passar a questionar o quanto algumas poucas falas restritas de um ou outro aluno de um grupo, ou de uma sala de aula com algumas dezenas de estudantes, realmente representam as idéias dos alunos, se não de todos, porém de uma boa parte deles, ou mesmo daqueles explicitados. A verdade é que, inferir uma aprendizagem mais profunda, ou que houve uma generalidade da idéia ou do conceito em foco, através da avaliação de um discurso singular, é querer fazer uma antecipação deveras arrojada, que pode, muitas vezes, não estar realmente demonstrada por outras formas de avaliação.

Um segundo ponto, que pensamos ser mais básico, é que encontramos na literatura argumentos contrários ao destaque do uso de atividades em grupo ou de um tipo único de atividade. De acordo com ela, vemos que, enquanto o primeiro estilo é preferido e efetivo para alguns estudantes, isto não acontece com outros. Vê-se que a natureza da aprendizagem individual é particularizada. Por exemplo, Pask (1976) observou que os indivíduos têm preferências quanto ao estilo de aprendizagem. Uns estudantes obedecem a um estilo holista, no sentido de que preferem formar uma visão mais global quando da resolução de problemas. Costumam trabalhar com várias hipóteses, simultaneamente, tendo por hábito adotar uma postura individualista de aprendizagem. Outros são serialistas, pois preferem integrar, passo a passo, tópicos separados daquele que está sendo aprendido e examinar, progressivamente, uma hipótese por vez. Enquanto os primeiros têm uma preferência em construir uma descrição geral do que é conhecido, os segundos têm uma postura mais operacional, procurando dominar detalhes dos processos e dos procedimentos. Da mesma forma, existem estudantes com personalidade competitiva que apreciam demonstrar sua capacidade intelectual. Por outro lado, há aqueles que são pessimistas sobre suas habilidades, ou que são metodicamente estudiosos, gastando várias horas de estudo. Lawson (2000: 594) nos atenta para dois trabalhos que mostram estudos detalhados indicando que pessoas criativas tendem a mostrar características de pouca sociabilidade, são brigões, hostis e em processo de grande esforço criativo, freqüentemente se encontram fisicamente isolados de outros indivíduos. Kempa \& Martin-Diaz (1990a, b) chegam a dividir em quatro padrões de motivação a preferência dos estudantes pelos modos de instrução da ciência. São eles: 1) os executores, 2) os curiosos, 3) os cumpridores de tarefas, 4) os sociais. Estes últimos são os que mostram maior afinidade por atividades em grupo, enquanto os penúltimos preferem um ensino didático convencional, com experimentos sustentados por instruções. Os segundos acham melhor aprender a partir de livros, por descoberta, e fazer mais atividades práticas. Por final, no caso dos executores, não há identificação de qualquer das preferências anteriores,

\footnotetext{
${ }^{6}$ Tese que afirma o predomínio das pressões exclusivas do meio ou da aquisição externa.
} 
parecendo que qualquer estilo lhes é indiferente.

Dentro ainda da questão da diversidade e da complexidade envolvida no ambiente de sala de aula e do problema da defesa de um único estilo de atividade com os alunos, temos o trabalho de Villani \& Barolli (2000). De inspiração psicanalítica, vemos que este trabalho propõe um conjunto de sete patamares definidos a partir das representações que os estudantes fazem acerca do conhecimento, do professor, dos colegas, da escola, etc.. Tais patamares fornecem indícios de uma relação mais ou menos estável do indivíduo com o seu próprio processo de aprendizagem (p.205). São eles: 1) Rejeição Direta; 2) Indecisão; 3) Demanda Passiva; 4) Risco; 5) Aprendizagem Ativa; 6) Avanço; 7) Procura Criativa. Esses patamares mostram uma variação que vai desde a rejeição e o desprezo do conhecimento escolar pelo estudante, em que o professor é considerado um inimigo, onde a escola e o conhecimento não representam nenhum valor, traduzindo-se num comportamento do aluno de desrespeito à ordem vigente, em que a motivação e o interesse estão nas emoções fortes fora da escola, até uma caracterização de resolução autônoma de problemas pelo estudante, onde o professor passa a ser mais um assessor e, talvez agora, um mediador "strito sensu", ajudando os alunos a localizar e avaliar as informações, onde a produção do conhecimento está orientada no sentido de busca da verdade e de ultrapassar o conhecido (ibid.: 141).

Em outras obras ainda (Shade 1982; Swisher \& Deyhle 1987; Huber \& Powewardy 1990), vê-se que as características cognitivas e de aprendizagem de grupos de minorias étnicas e lingüísticas são diferenciadas do grupo social dominante, e que a melhoria da aprendizagem dessas minorias é afetada quando somente o estilo do grupo dominante é valorizado. Para finalizar, sem querer esgotar o que foi colocado, é possível mencionar a influência devida à própria instituição, quando cria hábitos escolares que se mostram, mais tarde, nos graus posteriores, impecilhos ao processo formativo. Nesse sentido, um antigo trabalho de Schonell et al. (1962), realizado na Austrália, verificou que crianças provenientes de escolas em que a ênfase era a instrução formal, achavam extremamente difícil ajustar-se às condições universitárias mais abertas. Mais preocupante, é um outro resultado mais recente encontrado por Baird \& Mitchell (1986) naquele mesmo país, mostrando alunos pedindo a volta do ensino tradicional, por não estarem dispostos "a pensar".

Em suma, todos os trabalhos mencionados indicam que os estudantes variam em suas motivações e preferências, no que se refere ao estilo ou ao modo de aprender, e mesmo na sua relação com o conhecimento. E isso, sem mencionar as suas habilidades mentais específicas, maturação lógica (Piaget \& Inhelder 1976), ritmos de aprendizagem, nível de motivação e interesse para uma determinada disciplina, persistência dedicada a um problema, experiências vividas pelo grupo social a que pertencem. Estes fatores certamente influenciam, entre outros, na qualidade e na profundidade da aprendizagem. Por conseguinte, é questionável uma única estratégia educacional, que só daria conta das necessidades de um tipo particular de aluno ou alunos e não de outros.

Outro ponto de apreciação a ser feito do nosso levantamento refere-se à difundida orientação pedagógica construtivista que incentiva a extração das idéias prévias dos estudantes. Para Jenkins (2000: 602), o motivo deste procedimento está longe de se tornar claro. Ele questiona se a função dessas idéias é a de subsidiar o professor no planejamento de ações em resposta a elas, ou o propósito é ajudar os estudantes a clarificar os seus próprios pensamentos. Para ele, o entendimento dos estudantes sobre os fenômenos naturais são válidos e devem ser tratados com respeito ${ }^{7}$ e, em muitos casos, podem ser usados como ponto de partida para que se alcance os objetivos propostos para a atividade selecionada, podendo esta variar, desde atividades de discussão em sala de aula, até trabalhos experimentais em laboratório.

Mas, Jenkins (opus cit.) lembra, prontamente, que alguns conceitos como força, energia, potência, gravidade ou massa, por fazerem parte das experiências e linguagem diárias dos alunos, não é difícil que estes as tenham, pelo contrário, é esperado que tenham alguma noção ou idéia de alguns desses conceitos. No entanto, outros conceitos como íon, radiação eletromagnética, oxidação, energia livre ou equilíbrio químico, que se encontram longe da experiência diária, torna-se mais difícil que seja adotado o procedimento de levantamento das idéias dos alunos, se não impossível (p. 603).

Somado ao que foi dito, estende-se um outro ponto importante. Fishler \& Lichtfeldt (1991) observam que no estudo da mecânica quântica é importante não partir, como é comum se fazer, dos simplificados, intuitivos e ilustrativos modelos da velha mecânica quântica, que são mais próximos da experiência diária dos alunos. Os autores concluem que quanto mais esses conceitos são reforçados em classe, mais impossível fica a superação dos mesmos. Para eles, a solução didática conveniente é apresentar diretamente aos alunos os conceitos antiintuitivos da mecânica quântica, o mais cedo possível, evitando assim o encorajamento de conceitos que contradizem o seu entendimento (p.241).

Dentro disso ainda, adicionemos dois questionamentos que podem ser incômodos para os entusiasmados com um certo discurso construtivista mais doutrinário. Primeiro, não seria possível ao professor, em muitas situações, aproveitar-se das pesquisas sobre as concepções alternativas e simplesmente descrever para os alunos como os mesmos em geral pensam, perguntando, em seguida, as suas opiniões a respeito disso, solicitando

\footnotetext{
${ }^{7}$ Ver também mais à frente.
} 
uma comparação crítica dessa forma de pensar com a do conhecimento estabelecido? Tal procedimento violentaria os princípios construtivistas? Talvez esta fosse uma potencial alternativa para o consumo de muito tempo e do conseqüente pouco conteúdo que caracteriza uma das críticas ao construtivismo (Airasian \& Walsh 1997: 448; Jenkins 2000: 605). Uma segunda questão afronta, de certa forma, o fundamento subjetivista construtivista radical. Recordemos que este fundamento afirma que "desde que os indivíduos produzem o seu próprio conhecimento através de suas crenças $e$ experiências, todo conhecimento é uma tentativa, subjetivo e pessoal" (Airasian \& Walsh 1997: 445c). Tendo isso em consideração, fica difícil entender a larga constatação das pesquisas em educação científica, segundo a qual as concepções alternativas têm propensão a obedecer um padrão essencialmente comum que independe do sujeito, da idade, da escolaridade, do contexto social e que chega a atravessar períodos históricos, isto, pelos menos, no que se refere a certos conteúdos (Chi 1991).

Muito do que foi dito até o momento, conduz à questão da aparente desconsideração de redações construtivistas em reconhecer a autoridade do professor na disciplina que está ministrando e de seu papel de contraposição às idéias dos alunos. Na tentativa de justamente opor-se às antiquadas pedagogias autoritárias centradas em quem ensina e, por outro lado, na idéia de um aprendiz passivo, subordinado e calado, os ideais de uma determinada leitura construtivista parecem igualar o discente ao docente, o formador ao formando, o aprendiz ao mestre. Certamente que, e isso se aprofunda nos níveis de ensino e aprendizagem escolares básicos, há ou deveria haver uma assimetria, comparativamente, de quem detém o conhecimento com quem não o detém. O professor, considerado o âmbito curricular da sua disciplina, sabe muito mais do que o seu aluno; foi preparado para isso. Num sentido geral, quando nos encontramos numa situação de aprendiz, confiamos "a priori" em quem nos ensina, ou seja, confia-se no saber do mestre, imaginando que este é detentor de uma formação competente no paradigma que nos está introduzindo, sem que isso se configure em autoritarismo. Muitas vezes, como aponta Villani et al. (1997), essa confiança no professor por parte do aluno pode ser fundamental para a aprendizagem. E, ademais, quando se reconhece e chega-se mesmo a admirar a competência do profissional da disciplina que se está estudando, é bem provável que se vê criado um caminho mais efetivo, fácil e direto para as mudanças e construções conceituais. Referenciando-nos em Perrenoud (2000: 118), acreditamos que exista uma diferença conceitual entre respeitar a idéia do aluno e considerá-la. Quando se dá à palavra respeitar o sentido de não intervir, não modificar, confunde-se respeitar as pessoas com não-intervenção, pretendendo-se afastar temores autoritários. Há, subjacente a essa idéia, um sentido de situar no mesmo plano epistemológico as idéias dos alunos às científicas, reiterando-se, com isso, as bases relativistas da ideologia construtivista. Por conseguinte, romper com o autoritarismo pedagógico, aspirando a defesa de um ensino significativo, não implica em respeitar as idéias dos alunos, mas sim, considerá-las, com a clara intenção pedagógica de controlar e avaliar o desenvolvimento da aprendizagem.

Postas as colocações dos últimos parágrafos, queremos enfatizar que a extração das idéias prévias dos alunos, existentes ou não, tem assegurada uma finalidade instrucional, traduzida nos dois pontos de Jenkins anteriores: primeiro, na medida em que se perscruta os pensamentos do aluno, permite-se saber o que este realmente "aprendeu" do que se queria que ele houvesse aprendido, sugerindo planos de ações a partir disso; segundo, na perspectiva de clarificar os próprios pensamentos dos estudantes, a extração de idéias tem como maior objetivo e relevância fazer com que o aprendiz traga para o nível do consciente conhecimentos intuitivos, de modo a escapar-lhes do poder de comando.

Detenhamo-nos, agora, na questão específica do conteúdo e do tempo de aprendizagem a ele dedicado. Não é difícil verificar que vários escritos construtivistas sobre a educação escolar argumentem no sentido da redução do conteúdo (Jenkins 2000: 605), passando o mesmo a ser secundário no processo de ensinoaprendizagem. Para eles, o problema do conteúdo é resultado de uma disseminada idéia que releva a real compreensão e a maior duração, diante do que é pejorativamente chamado de ensino superficial, frívolo e de curta duração. Antes de mais nada, apontemos que Jenkins (opus cit.) põe em dúvida esse tipo de entendimento, dizendo que não fica claro qual a evidência empírica, se é que existe evidência de qualquer tipo que substancie afirmações desse tipo (p. 605). Assim, o método construtivista de ensino, por ser consumidor de bastante tempo, acarreta uma cobertura relativamente pequena de conteúdos (Airasian \& Walsh 1997: 448; Jenkins 2000: 605). Este não compromisso maior com o conteúdo e, consequentemente, com o cumprimento do currículo, talvez se justifique na medida em que uma leitura construtivista, como dissemos, entende que não há verdades ou que não há conhecimentos mais corretos e que eles são relativos ao contexto social e cultural.

Evidentemente, é razoável a preocupação com um ensino enciclopédico, abstrato, compartimentado, que não se vê compromissado com a vida, com a cidadania, com a tecnologia, com os processos, pontos, principalmente este último, de maior relevância quando se trata do nível fundamental escolar e médio. Mas, deve-se pensar numa ponderação razoável entre, de um lado, a qualidade de aprendizagem do conteúdo e, de outro, a quantidade de conteúdo mínimo a ser ministrado, sabendo que isso é, para o ensino médio, sem falar do ensino superior ou técnico, este com suas habilidades manuais, muitas vezes, uma preocupação de maior interesse. Assim, fica a preocupação de se levar um ensino 
rigidamente baseado nos fundamentos de uma leitura construtivista que, talvez, se adeqüe mais a um nível (Jenkins 2000: 607) ou, mesmo, a uma condição escolar, do que a qualquer caso, indiscriminadamente.

Em suma, as estratégias instrucionais do construtivismo radical, que procuram encontrar exclusivos caminhos, tendo por base um vagar através de uma exploração intelectual autônoma, são questionáveis quanto à sua efetividade. Da mesma forma que o ensino tradicional objetivista-empirista, ao advogar a exclusividade das prescrições de um ensino mecânico, ritualista ou apenas de observação e de audição, centrado exclusivamente no professor, falha em reconhecer o papel ativo do aprendiz, também as concepções pedagógicas desses construtivistas, fundamentalmente, falham ao não perceberem que essa abordagem pode levar a uma postura indutivista da aprendizagem.

Algumas interpretações construtivistas parecem não reconhecer, igualmente, a possibilidade de existirem alunos que não se adaptam pedagogicamente a um determinado estilo de ensino, deixando de desconsiderar, na prática, um princípio central construtivista que procura entender que os estudantes, em sala de aula, partem de condições iniciais desiguais, pois têm trajetórias de vida cognitiva, motivacional e emocional distintas. Os construtivistas que se encaixam nesta análise em particular, temem reconhecer explicitamente, por exemplo, um papel efetivo para as exposições orais, para as demonstrações, para "o ver" e "o mostrar", como capazes de construir e orientar o conhecimento. Não admitem, ao menos abertamente, a possibilidade do professor prover verbalmente o estudante com informações prévias e diretas que lhe preencham lacunas ${ }^{8}$ e lhe ampliem as relações de significado, capacitando-o a dar sentido às suas percepções que, de outra forma, focariam elementos desnecessários aos objetivos educacionais (como o caso citado do movimento browniano).

O instrumental teórico do construtivismo radical, particularmente, é falho ao não reconhecer que a descrição dos objetos reais passa por idealizações que, no fundo, são processos de abstração não acessíveis ao experimento sensório e que, no caso do construtivismo social, não se chega a essas idealizações através de uma negociação coletiva, mas que, em sua grande maioria, precisam ser previamente "impostas" pelo professor, por serem antiintuitivas. Poderíamos perguntar, que tipo de experiência far-nos-ia imaginar e aprender os conceitos de ponto material, referencial inercial, rotacional de um campo, banda de valência, princípio da incerteza, etc.. Ou, ainda, que tipo de interação entre um grupo de aprendizes leigos isolados dos "experts", dos manuais, poderia conduzir aos mesmos conceitos, ou como um noviço ou grupo de noviços construiriam esses conceitos distantes do senso comum, por meio da simples negociação, no sentido de barganha conceitual com um "expert". Assim, como critica Irzik (2000: 634), não dizer aos estudantes que conceitos construir ou como construí-los não é uma virtude, mas um vício da teoria construtivista.

Não há o que discutir da óbvia noção de que o conhecimento é construído como um ato pessoal, mas não há a menor dúvida de que o processo pedagógico para essa construção é altamente complexo, pouco entendido e longe de ser trivial (Osborne 1996: 66). Vemos isso, quando certos construtivistas como Posner et al.(1982) e Hewson \& Thorley (1989) chegam a imaginar uma aproximação epistemológica entre o aprender ciência e o fazer ciência. Porém, advertem Osborne (1996: 67), Ogborn (1997: 122) e Nola (1997: 79), entre outros, que não existe uma necessária conexão funcional epistemológica entre fazer ciência e os métodos pelos quais ela é aprendida e, principalmente, ensinada para os não cientistas. Em termos mais gerais, o último autor comenta sobre a sua preocupação quando se procura estabelecer uma falsa ligação entre a filosofia relacionada com a natureza do conhecimento científico, particularmente, e a educação científica, e avalia que precisamos separar, principalmente no construtivismo, a interpretação teórica da formação das teorias científicas, da teoria de como os estudantes aprendem a ciência (ibid.: 57, 78). Em última instância, em relação a isso, é preciso reconhecer que nenhum compromisso, com uma possível visão parcial epistemológica da ciência, é justificativa suficiente para exclusivamente nos orientarmos na maneira de ensiná-la. Osborne, por sua vez, assim como Matthews (2000), num sentido mais geral, chamam a atenção para o fato de que o construtivismo, como uma visão de aprendizagem, é situado como uma grande teoria, aplicável a todas as circunstâncias, e não um simples referencial de valor parcial e limitado. Numa linha diferente de critica, o primeiro autor, particularmente, observa o emprego generalizado da metacognição, como mecanismo para descrever o pensamento gerado na aprendizagem e chega a perguntar se o uso desse mecanismo traz benefícios para todos os aprendizes, indiscriminadamente, assim como para todas as idades (Osborne 1996). A pertinência dessa crítica pode ser verificada em Brown (1987), onde encontramos a indicação de vários trabalhos mostrando que, antes da adolescência, a metacognição tem pouca eficácia cognitiva.

\section{Conclusões}

Este trabalho procurou trazer para o debate algumas proposições centrais de uma leitura da pedagogia construtivista e algumas de suas indicações instrucionais para o ensino de ciências, buscando expô-las à crítica ou, simplesmente, dar-lhes uma outra fundamentação.

\footnotetext{
${ }^{8}$ Aqui, a importância durante a instrução de se levar em conta o papel da memorização de informações e da aquisição de habilidades profissionais específicas, não pode ser trivialmente desconsiderada, como já tivemos a oportunidade de mencionar.
} 
Com isso, espera-se que afirmações e orientações que estão sendo disseminadas por um sedutor discurso construtivista deixem de se tornar aforismos imaturos ou incontrolados, principalmente quando empregados pelos que são responsáveis pelo ofício de ensinar.

Sem dúvida, o construtivismo deixa um legado pedagógico de considerações importantes, que devem ser apropriadas. Mas aí, em imaginar que estratégias instrucionais complementares e variadas, que não confluem em direção aos cânones de uma visão construtivista particular, significa a condução de uma aprendizagem leviana, de pouca provocação cognitiva, parece ser um certo exagero, como pretendemos mostrar. Mesmo porque, como já nos advertia Millar (1989) não existe uma conexão necessária entre um modelo de aprendizagem construtivista e um modelo específico de instrução, e sugere que qualquer sucesso sentido pelos professores com o esquema de ensino construtivista, pode vir a estar muito mais correlacionado com o método ativo de aprendizagem usado, do que com o mapeamento do modelo de aprendizagem baseado num modelo de instrução particular (p. 589).

Por conseguinte, procedimentos que estimulam a reflexão, a tomada de decisões, o questionamento, o debate, etc., que certamente levam ao pensamento crítico e a uma educação científica significante, metas obrigatórias de todo ensino de qualidade não são exclusividade construtivista e, muito menos, precisam obrigatoriamente prender-se ao monopólio de uma interpretação construtivista unilateral. Neste caso, como ao igualmente superado ensino transmissivista puro, porém em tom de crítica para este, vale, por fim, a lei de Claparède, que afirma que quanto mais suavemente utilizamos uma relação em ação, menos temos consciência dessa relação; a consciência que tomamos do que estamos fazendo varia na proporção direta das dificuldades para nos adaptarmos a uma situação, e é dentro desse contexto que os procedimentos citados, no fundo, se inserem.

\section{Referências}

AIRASIAN, P. W. \& WALSH, M. E. Constructivit Cautions, Phi Delta Kappa, 78, 6, 444-449 (1997).

BAIRD, J.R. \& MITCHELL, I.J. Eds. Improving the quality of teaching and learning: an australian case study - the PEEL project, Monash University, Melbourne (1986).

BITTINGER, M. L. A review of discovery, The mathematics Teacher, 61, 140-146 (1968).

BROWN, A. Metacognition, executive control, selfregulation, and other mysterious mechanism. In F. Weinert \& R.H. Kluwe(Eds.), Metacognition, motivation, and understanding. Hillsdale, NJ: Lawrence Erlbaum, 65-113 (1987).

CHALMERS, A. A fabricação da ciência, Editora UNESP, São Paulo, SP (1994).
CHI, M. T .H. Conceptual change within and across ontological categories: Examples from learning and discovery in science, in R. Giere (ed.). Cognitive Models of Science: Minnesota Studies in the Philosophy of Science, University of Minnesota Press, Minnesota (1991).

CHINN, C. A. \& BREWER, W. F. The role of anomalous data in knowledge acquisition: a theoretical framework and implications for science instruction. Review of Educational Research, 63, 1, 1-49 (1993).

CLEMENT ET AL. Overcoming students' misconceptions in physics: the role of anchoring intuitions and analogical validity. Proceedings of the Second International Seminar. Misconceptions and Educational Strategies in Science and Mathematics, 3, 84-97 (1987).

DI SESSA, A. A. Unlearning Aristotelian physics: a study of knowledge-based learning. Cognitive Science, 6, 37-75 (1982).

DRIVER, R. Students' conceptions and the learning of science. International Journal of Science Education, 11, Especial Issue, 481-490 (1989).

DRIVER, R., HILARY, A. LEACH, J., MORTIMER, E., \& SCOTT, P. Constructing scientific knowledge in the classroom. Educational Researcher, 23, 7, 5-12 (1994).

EDWARDS, D., \& MERCER, N. Common knowledge. The development of understanding in the classroom. Routledge. London and New York (1987).

FEYERABEND, P. Contra o método. Francisco Alves, $3^{a}$ edição, Rio de Janeiro (1989).

FISCHLER, H. \& LICHTFELDT, M. Learning quantum mechanics, In: Research in Physics Learning: Theoretical Issues and Empirical Studies. Proceedings of an International Workshop Held at the University of Bremen, march 4-8, 1991. Duit, R. et al. (Eds), 240-251 (1991).

FRIEDLANDER, B.Z. A psychologist's second thoughts on concepts, curiosity, and discovery in teaching and learning, Harvard Educational Review, 35, 18-38 (1965).

GLASERSFELD, E. V. Cognition, construction of knowledge and teaching. Syntheses, 80, 121-140 (1989).

HARDY, M. D. \& TAYLOR, P. C. Von Glasersfeld's radical constructivism: a critical review. Science \& Education, 6, 1-2, 135-150 (1997).

HEWSON, P. W. \& THORLEY, N. R. The conditions of conceptual change in the classroom. International Journal of Science Education, 11, Special Issue, 541-553(1989).

HOLLON, R. E., ROTH, K. J. \& ANDERSON, C. W. Science teachers' conceptions of teaching and learning. Advances in Research on Teaching, JAI Press Inc., V2, 145-185 (1991).

HOWE, A. C. Development of science concepts within a Vygotskian framework. Science Education, 80, (1), 35-51 (1996).

HUBER, T. \& PEWEWERDY, C. Maximising learning for all students: A review of the literature on 
learning modalities, cognitive styles and approaches to meeting the needs of diverse learners. Washington, DC: ERIC Clearinghouse on Teacher Education (ED 324289) (1990).

IRZIK, G. Back to basis: a philosophical critique of constructivism, Science \& Education, 9, 621-639 (2000).

JENKINS, E. W. Constructivism in school science education: powerful model or the most dangerous intellectual tendency?, Science \& Education, 9, 599-610 (2000).

KARMILOFF-SMITH, A. \& INHELDER, B. If you want to go ahead, get a theory. Cognition, 3, 195-212 (1974).

KEMPA, R. F. \& MARTIN-DIAZ, M. Student's motivational traits and preference for different instructional modes in science. Part 1. International Journal of Science Education, 12, 194-203 (1990a).

KEMPA, R. F. \& MARTIN-DIAZ, M. Student's motivational traits and preference for different instructional modes in science. Part 2. International Journal of Science Education, 12, 205-216 (1990b).

LABURÚ, C. E. A construção do conhecimento em sala de aula. Tese de doutorado. Faculdade de Educação da USP. São Paulo, SP (1993).

LABURÚ, C. E. La crítica en la enseñanza de las ciencias: constructivismo y contradicción. Enseñanza de las Ciencias, 14, (1), 93-101 (1996).

LABURÚ, C. E.; ARRUDA, S. M. \& NARDI, R. Os programas de lakatos: uma leitura para o entendimento da construção do conhecimento em sala de aula em situações de contradição e controvérsia, Ciência $\mathscr{G}$ Educação, 5, 2, 23-38 (1998).

LABURÚ, C. E.; CARVAHLO, M. \& BATISTA, I. L. Controvérsias Construtivistas, Caderno Catarinense de Ensino de Física, no prelo, 18, 2, 152-181 (2001).

LABURÚ, C. E.; SILVA, M. R Do relativismo no ensino de física ao objetivismo na física, Investigações em Ensino de Ciências, endereço eletrônico: http://www.if.ufrgs.br/public/ensino/vol5/n2/v5_n2_a3.htm 5, 2, 1-35 (2000).

LAWSON, A. E. How do humans acquire knowledge? And what does that imply about the nature of knowledge?, Science \&3 Education, 9, 577-598 (2000).

MATTHEWS, M. R. Constructivism and empiricism: An incomplete divorce. Research in Science Education, 22, 299-307 (1992).

MATTHEWS, M. R. Science teaching. The role of history and philosophy of science. Philosophy of Education. Research Library. Routledge. Cortez Editor. NY. (1994).

MATTHEWS, M. R. Constructivism and science education: an evaluation, Atas VII Encontro de Pesquisa em Ensino de Física, Florianópolis, SC, março (2000).

MORTIMER, E. F. \& MACHADO, A.H. As linguagens na sala de aula de química e ciências. In:
VIII Encontro Nacional de Ensino de Química. VIII Encontro Centro-Oeste de Debates sobre o Ensino de Química e Ciências. Cadernos de Resumos e Anais, Campo Grande, MS, 28-37 (1996).

MORTIMER, E. F. \& MACHADO, A.H. Anomalies and Conflicts in classroom discourse, Science Education, 84, 429-444 (2000).

NEILL, A. S. Liberdade sem medo (Summerhill), $18^{a}$ edição, São Paulo, IBRASA (1979).

MILLAR, R. Constructive criticism. International Journal of Science Education. Special Issue, 11, 5, 587596 (1989).

NOLA, R. Constructivism in science and science education: a philosophical critique. Science 8 Education, 6, 1-2, 55-83 (1997).

NUSSBAUM, J. \& NOVICK, S. Alternative frameworks, conceptual conflict and accommodation: toward a principled teaching strategy. Instructional Science, 11, 183-200 (1982).

OGBORN, J. Constructivist metaphors of learning science. Science $\&$ Education, 6, 1-2, 121-133 (1997).

OLIVEIRA, M. K. Vygotsky, aprendizado e desenvolvimento. Um processo sócio-histórico. Série Pensamento e Ação no Magistério. Editora Scipione, São Paulo, SP (1993).

OSBORNE, J. F. Beyond constructivism. International Journal of Science Education, 80, (1), 53-82 (1996).

PASK, G. Styles and strategies of learning. British Journal of Educational Psychology, 46, 128-148 (1976).

PERRENOUD, P. Pedagogia diferenciada: das intenções à ação, Porto Alegre, Artmed Editora, 113-130 (2000).

PIAGET, J. \& INHELDER, B. Da lógica da criança à lógica do adolescente, Editora Pioneira de Ciências Sociais, São Paulo (1976).

PHILLIPS, D. C. Coming to grips with radical social constructivisms. Science \& Education, 6, 1-2, 85104 (1997).

, POPPER, K. A lógica da pesquisa científica, Editora Cultrix, São Paulo (1972).

POSNER,G.J., STRIKE, K. A., HEWSON, P. W. \& GERTZOG, W. A. Accommodation of scientific conception: Toward a theory of conceptual change. Science Education, New York, 66, (2), 221-227 (1982).

REGO, T. C. Vygotsky, uma perspectiva históricocultural da educação, Editora Vozes, $6^{a}$ Edição, Petrópolis, RJ (1994).

ROWELL, J. A. Laboratory counter examples and the growth of understanding in science. European Journal of Science Education, 5, (2), 203-215 (1983).

ROWELL, J. A. Equilibration: developing the heart core of the piagetian research program. Human Development., 26, 61-71 (1983a).

ROWELL, J. A. A piagetian epistemology: equilibration and the teaching of science. Synthese. Netherlands, 80, 141-162 (1989). 
SCOTT, R., ASOKO, H. M. \& DRIVER, R. Teaching for conceptual change: a review of strategies. In: Research in Physics Learning: Theoretical Issues and Empirical Studies. Proceedings of an International Workshop held at the University of Bremem, Duit, R. et al.(Eds), 310-329 (1991)

SHADE, B. Afro-American cognitive style: A variable in school success. Review of Educational Research, 52, (2), 219-244 (1982).

SCHONELL, F.J., ROE, E. \& MEDDLETON, I. G. Promise and performance. Brisbane and London, 218-221 (1962).

STAVY. R. Using analogy to overcome misconceptions about conservation of matter. Journal of Research in Science Teaching, 28, (4), 305-313 (1991).

SWISHER, K. \& DEYHLE, D. Styles of learning and learning of styles: Educational conflicts for American Indian/Alaskan native youth. Journal of Multilingual and Multicultural Development, 8, (4), 345-360 (1987).

VILLANI, A. \& BAROLLI, E. Interpretando a aprendizagem nas salas de aula, Atas $23^{a} A N P E D$, CDROM, GT 0413pp. (2000).

VILLANI, A., BAROLLI, B., CABRAL, T. C. B.; FAGUNDES, M. B.\& YAMAZAKI, S. C. Filosofia da ciência e psicanálise: analogias para o ensino de ciências. Cadernos Catarinense de Ensino de Física, v 14, 1, 37-55 (1997). 